\title{
SHEAR BUCKLING EVALUATION IN STEEL PLATE GIRDERS WITH RIGID END POSTS SUBJECTED TO ELEVATED TEMPERATURES
}

\author{
André Reis, Nuno Lopes, Paulo Vila Real \\ RISCO, University of Aveiro, Department of Civil Engineering, Aveiro, Portugal
}

\begin{abstract}
The current study intends to analyse the behaviour of steel plate girders with rigid end posts subjected to elevated temperatures, aiming the assessment of the ultimate shear strength in case of fire. A parametric numerical study was performed involving a wide range of cross-section's dimensions, plate girders' aspect ratios and steel grades. Plate girders were numerically tested at both normal and elevated temperature, being considered three different uniform temperatures. The influence of the geometrical imperfections, as well as the residual stresses, was taken into account. Finally, the numerical results were compared to the Eurocode 3 (EC3) prescriptions, adapted to fire situation by the direct application of the reduction factors for the stress-strain relationship of steel at elevated temperatures. It was shown that the EC3 design rules should be improved because they are not conservative, conducting to unsafe results.
\end{abstract}

Keywords: fire, ultimate shear strength, rigid end posts, numerical analysis, Eurocode 3.

\section{INTRODUCTION}

Recently there has been an increase on the use of steel plate girders, due to their capacity to support high loads over long spans. Thanks to its light weight, plate girders are economically competitive solutions being commonly applied in buildings and bridges. For material efficiency, they usually have slender webs when compared to the ones on commercial hot rolled profiles, making them susceptible to the occurrence of shear buckling, a very important phenomenon on the design of steel structural elements with thin-walled cross-sections. Hence, shear buckling has been widely studied in the last decades leading to the implementation of the Rotated Stress Field Method (Höglund, 1997) in Part 1-5 of EC3 (CEN, 2006) for the design at normal temperature of steel plate girders under shear. However, the occurrence of shear buckling in steel structural members subjected to elevated temperatures has not received the same attention and it has not yet been shown if the prescriptions adopted in Part 1-5 of EC3 may be directly applied to fire design. In this study, due to the lack of rules in Part 1-2 of EC3 (CEN, 2005) for the shear buckling verification in case of fire, a simple methodology based on the design rules at normal temperature, adapted to fire situation by the direct application of the reduction factors for the steel stress-strain relationship at elevated temperatures, was used.

The main goal of this work is to study the shear response of steel plate girders with rigid end posts in fire situation, assessing if the procedure from Part 1-5 of EC3 for the design at normal temperature may be adapted for fire design. For that purpose, a parametric numerical study was performed using a calibrated numerical model (Reis et al., 2013) in the FEM software SAFIR (Franssen, 2005). The influence of the geometric imperfections was taken into account considering the first buckling modes. Furthermore, the residual stresses were also taken into account.

Simply supported plate girders with nine different cross-sections and a wide range of aspect ratios $\left(\mathrm{a} / \mathrm{h}_{\mathrm{w}}\right)$ were analysed at normal temperature and subjected to different uniform temperatures $\left(350^{\circ} \mathrm{C}\right.$, $500^{\circ} \mathrm{C}$ and $600^{\circ} \mathrm{C}$ ) under steady-state conditions, i.e., the temperature is considered constant while the load is increased until failure. Four different steel grades were considered in a total of 432 numerical analyses. Finally, the numerical results are compared with the analytical ones obtained using the procedures implemented in EC3 for the design of steel plate girders. 


\section{EC3 DESIGN RULES}

The ultimate shear strength of plate structural elements must be checked according to Part 1-5 of EC3 (CEN, 2006), where prescriptions for the safety analysis of both shear buckling and interaction between shear and bending may be found.

\subsection{Shear buckling}

The shear buckling resistance must be assessed when $h_{w} / t_{w}>72 \varepsilon / \eta$ for unstiffened webs and $h_{w} / t_{w}>31 \varepsilon / \eta \sqrt{k_{\tau}}$ for stiffened webs, where $h_{w}$ is the web height, $t_{w}$ is the web thickness, $\varepsilon$ is a parameter that depends on the steel yield strength and on the Young's modulus, $\eta$ is a coefficient related to the strain hardening and $k_{\tau}$ is the shear buckling coefficient of the web plate. If these conditions are fulfil it is still necessary to provide transverse stiffeners at the supports.

The Rotated Stress Field Method (Höglund, 1997) is the basis of the shear design rules given in Section 5 of Part 1-5 of EC3, where the shear design resistance is expressed as the sum of the web resistance to shear buckling and the flange contribution.

\subsection{Shear-bending interaction}

Regarding the interaction between shear and bending, it must be checked, according to Section 7 of Part 1-5 of EC3, when the acting shear effort exceeds half of the design value of the contribution from the web to shear buckling, which occur in some of the tests presented here.

\subsection{Design in fire situation}

No specific rules for the ultimate shear strength verification in case of fire are given in Part 1-2 of EC3 (CEN, 2005). Due to this absence of guidance, the use of the design rules at normal temperature, adapted to fire situation by the direct application of the reduction factors for the stressstrain relationship of steel at elevated temperatures, is a simple procedure that may be used to assess the shear buckling resistance at elevated temperatures. In this procedure, $k_{y, \theta}$ is applied to take into account the reduction of the steel yield strength caused by the elevated temperatures, whereas $k_{E, \theta}$ is used to reduce the Young's modulus in Eq. (1) (Franssen \& Vila Real, 2010), for the calculation of the parameter $\varepsilon_{\theta}$ needed for the calculation of the plate slenderness in fire situation. Finally, $k_{0.2 p, \theta}$ is used for Class 4 sections to consider the reduction of the bending resistance at elevated temperatures. These reduction factors are given in Part 1-2 of EC3.

$$
\varepsilon_{\theta}=\sqrt{\frac{235}{k_{y, \theta} f_{y}}} \sqrt{\frac{k_{E, \theta} E}{210000}} \text { with } f_{y} \text { and } E \text { in }[\mathrm{MPa}]
$$

\section{NUMERICAL MODELLING}

\subsection{FEM model}

The numerical modelling was performed using SAFIR (Franssen, 2005), a FEM software developed at University of Liège for the simulation of the behaviour of structures subjected to fire. A threedimensional model was developed (see Fig. 1) to perform geometrically and materially nonlinear numerical analyses including imperfections (GMNIA). Four-node quadrangular shell elements were used in order to capture the local buckling phenomena typical of these slender cross sections. After performing a sensitivity analysis, a mesh with 30 divisions in the web, 10 divisions in the flanges and 100 divisions per meter of beam length was used. The horizontal displacement of the upper flange points was restrained in order to avoid the lateral torsional buckling. A concentrated load distributed on the entire web depth was applied at mid-span. The material model recommended in Part 1-2 of EC3 was used for the steel behaviour not considering the strain-hardening. It is important to note that this numerical model was previously validated against experimental tests from literature (Reis et al., 2013). 


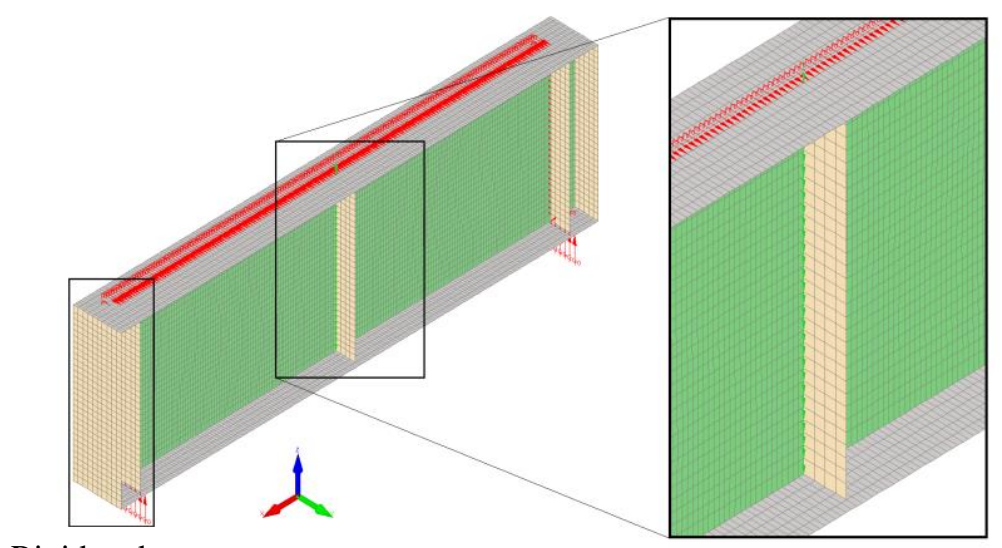

Rigid end post

Fig. 1 Numerical model

\subsection{Geometric imperfections and residual stresses}

Geometric imperfections are present in all steel structural members and influence their bearing capacity. These imperfections are mainly due to the profiles production and fabrication process. Consequently, it is necessary to take them into account in the numerical model. For this purpose, a linear eigenvalue buckling analysis is firstly performed to determine the lowest relevant buckling mode. The obtained shape is considered as the geometric imperfection and it is incorporated in the non-linear analysis. A geometric imperfections maximum amplitude equal to $80 \%$ of the essential manufacturing tolerances for welded profiles obtained from EN 1090-2 (CEN, 2011) was considered, as recommended in Annex C of Part 1-5 of EC3. This way, the maximum amplitude considered for the imperfections was $0.8 b_{f} / 100$ in the flanges and $0.8 h_{w} / 100$ in the web. As the global buckling was restrained by the application of lateral bracings in the upper flange, only local imperfections were taken into account in the numerical modelling. The first local buckling modes were obtained using the computer software CAST3M (CAST3M, 2012) and the programme RUBY (Couto et al., 2013) was used for the interface between CAST3M and SAFIR. Regarding residual stresses, the pattern typically observed on welded I-sections (ECCS, 1984) was used.

\subsection{Characteristics of the analysed plate girders}

Simply supported plate girders with rigid end-posts and $1.8 \mathrm{~m}$ length are studied in this work. Different distances between transverse stiffeners $(a)$ were considered. The stiffeners have thicknesses of 5, 10 and $12 \mathrm{~mm}$ (for I-300x $t_{w}-100 \mathrm{x} t_{f}, \mathrm{I}-600 \mathrm{x} t_{w}-200 \mathrm{x} t_{f}$ and I-900x $t_{w}-300 \mathrm{x} t_{f}$, respectively). Table 1 shows the dimensions and the material properties of the plate girders considered in the parametric numerical study. A total of 108 plate girders were analysed at $20^{\circ} \mathrm{C}$ and subjected to three different uniform temperatures $\left(350^{\circ} \mathrm{C}, 500^{\circ} \mathrm{C}\right.$ and $\left.600^{\circ} \mathrm{C}\right)$ under steady-state conditions, i.e., the temperature is considered constant while the load is increased until failure.

Table 1 Dimensions and material properties of the analysed plate girders

\begin{tabular}{|c|c|c|c|c|c|c|}
\hline Designation & $\mathrm{h}_{\mathrm{w}}[\mathrm{mm}]$ & $\mathrm{t}_{\mathrm{w}}[\mathrm{mm}]$ & $\mathrm{b}_{\mathrm{f}}[\mathrm{mm}]$ & $\mathrm{t}_{\mathrm{f}}[\mathrm{mm}]$ & $\mathrm{a}[\mathrm{mm}]$ & $\mathrm{f}_{\mathrm{y}}[\mathrm{MPa}]$ \\
\hline $\mathrm{I}-300 \times 1.5+100 \times 5.0$ & \multirow{3}{*}{300} & 1.5 & \multirow{3}{*}{100} & 5.0 & \multirow{9}{*}{$\begin{array}{c}300,600 \text { and } \\
900\end{array}$} & \multirow{9}{*}{$\begin{array}{c}235,275 \\
355 \text { and } 460\end{array}$} \\
\hline $\mathrm{I}-300 \times 2.0+100 \times 10.0$ & & 2.0 & & 10.0 & & \\
\hline $\mathrm{I}-300 \times 2.5+100 \times 10.0$ & & 2.5 & & 10.0 & & \\
\hline $\mathrm{I}-600 \times 3.0+200 \times 10.0$ & \multirow{3}{*}{600} & 3.0 & \multirow{3}{*}{200} & 10.0 & & \\
\hline I- $600 \times 3.5+200 \times 12.0$ & & 3.5 & & 12.0 & & \\
\hline $\mathrm{I}-600 \times 4.0+200 \times 12.0$ & & 4.0 & & 12.0 & & \\
\hline $\mathrm{I}-900 \times 4.0+300 \times 12.0$ & \multirow{3}{*}{900} & 4.0 & \multirow{3}{*}{300} & 12.0 & & \\
\hline $\mathrm{I}-900 \times 4.5+300 \times 15.0$ & & 4.5 & & 15.0 & & \\
\hline $\mathrm{I}-900 \times 5.0+300 \times 15.0$ & & 5.0 & & 15.0 & & \\
\hline
\end{tabular}




\section{DISCUSSION OF RESULTS}

\subsection{General considerations}

In analyzing and comparing the numerical results with the prescriptions of the EC3, three different zones were considered, as illustrated in Fig. 2. Plate girders exhibiting a shear dominant failure belong to zone 1, while plate girders revealing a bending dominant failure belong to zone 3 . Finally, plate girders with a combined shear plus bending failure belong to zone 2 . The ratio of shear force to bending moment for each zone of the shear-bending interaction diagram is given in Table 2 .

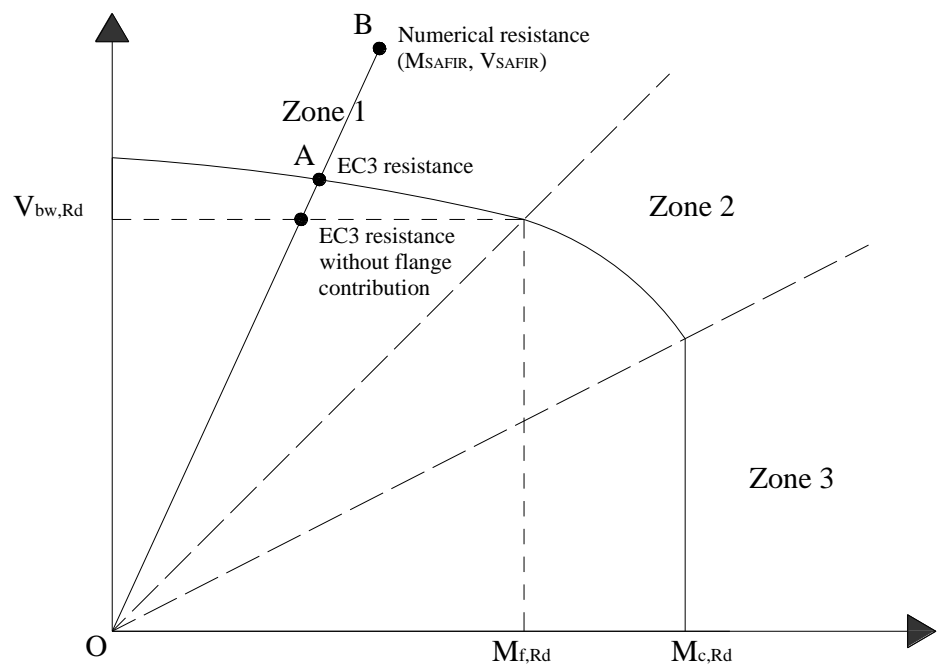

Fig. 2 Shear-bending interaction diagram - definition of zones 1, 2 and 3

Table 2 Zones classification of the shear-bending interaction diagram

\begin{tabular}{|c|c|}
\hline Zone & Expression \\
\hline 1 & $V_{S A F I R} / M_{S A F I R}>V_{b w, R d} / M_{f, R d}$ \\
\hline \multirow{2}{*}{2} & $V_{\text {SAFIR }} / M_{\text {SAFIR }} \leq V_{b w, R d} / M_{f, R d}$ \\
\hline & $V_{S A F I R} / M_{S A F I R} \geq 0.5 V_{b w, R d}\left(\sqrt{\left(1-M_{c, R d} / M_{p l, R d}\right) /\left(1-M_{f, R d} / M_{p l, R d}\right)}+1\right) / M_{c, R d}$ \\
\hline 3 & $V_{S A F I R} / M_{S A F I R}<0.5 V_{b w, R d}\left(\sqrt{\left(1-M_{c, R d} / M_{p l, R d}\right) /\left(1-M_{f, R d} / M_{p l, R d}\right)}+1\right) / M_{c, R d}$ \\
\hline
\end{tabular}

Since the precise shape of the shear-bending interaction diagram varies with both shear resistance and bending resistance, and since they are different for each plate girder, a single shear-bending interaction diagram must be drawn for each plate girder. For evaluating the design rules adopted in EC3, a proportional loading is assumed, i.e., the ratio of shear force to bending moment remains constant. The numerical results collected from zone 1 are used to compare with the shear buckling resistance predictions from Section 5 of Part 1-5 of EC3, while the numerical results collected from zone 2 are used to evaluate the expression of shear-bending interaction from Section 7 of Part 1-5 of EC3. The ratio by which each numerical data point exceeded or fell short of its respective shearbending interaction diagram was designated $\mathrm{U}_{\mathrm{EC} 3}$ (in Fig. 2, $U_{E C 3}=\overline{O B} / \overline{O A}$ ). This ratio will be used in Fig. 3. A value of $\mathrm{U}_{\mathrm{EC} 3}$ larger than 1.0 means a safe result and the numerical data point is located outside the shear-bending interaction diagram. This methodology follows the one presented in Saliba et al. (2014). Note that the interaction curve of zone 2 of Fig. 2 should be truncated by the vertical line that cuts the horizontal axis in $M_{p l, R d}$ in case of sections with Class 1 or 2 , or in $M_{c, R d}$ in case of sections with Class 3 or 4 , the elastic or the effective resistance bending moment respectively. Finally, for comparison with EC3 design expressions, the contribution from the web to shear buckling is calculated deducting the flange contribution, obtained according the EC3 expressions, from the ultimate shear strength directly predicted by the numerical model. 


\subsection{Comparison of results}

The results collected from the numerical parametric study were used to assess the current prescriptions of Part 1-5 of EC3 for shear design at normal temperature and adapted to elevated temperatures. The utilization ratio is presented in Fig. 3, while the shear buckling resistance of the web is shown in Fig. 4 for different aspect ratios of plate girders. As mentioned before, only plate girders with a shear dominant failure (zone 1) are presented in the charts of Fig. 4. Finally, in Fig. 5 it can be observed the failure modes of two of the analysed plate girders.
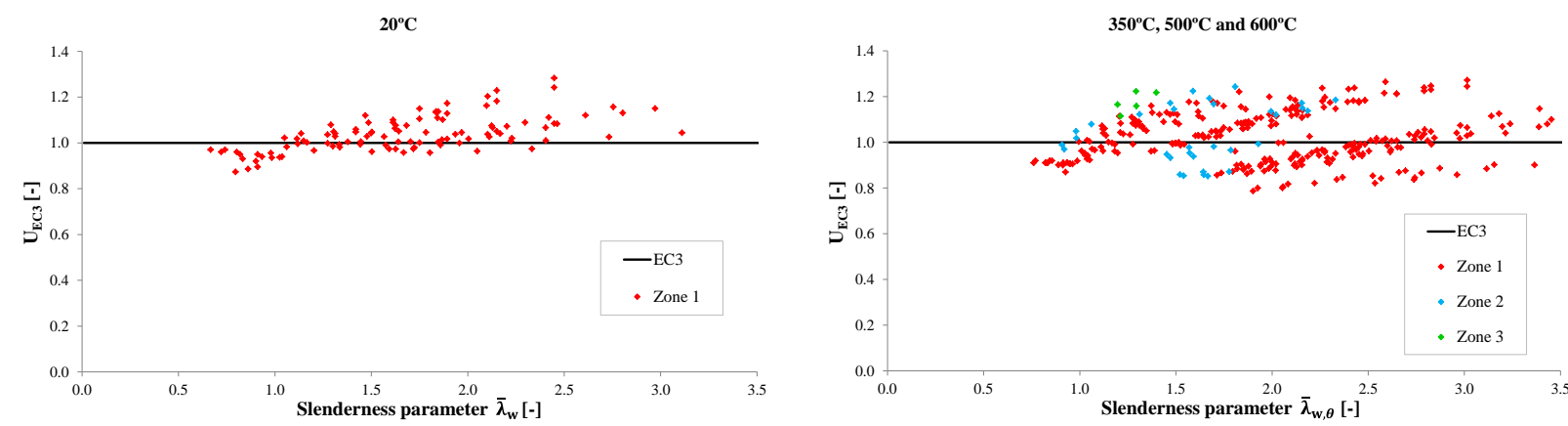

Fig. 3 Utilisation ratio (numerical/design resistance)
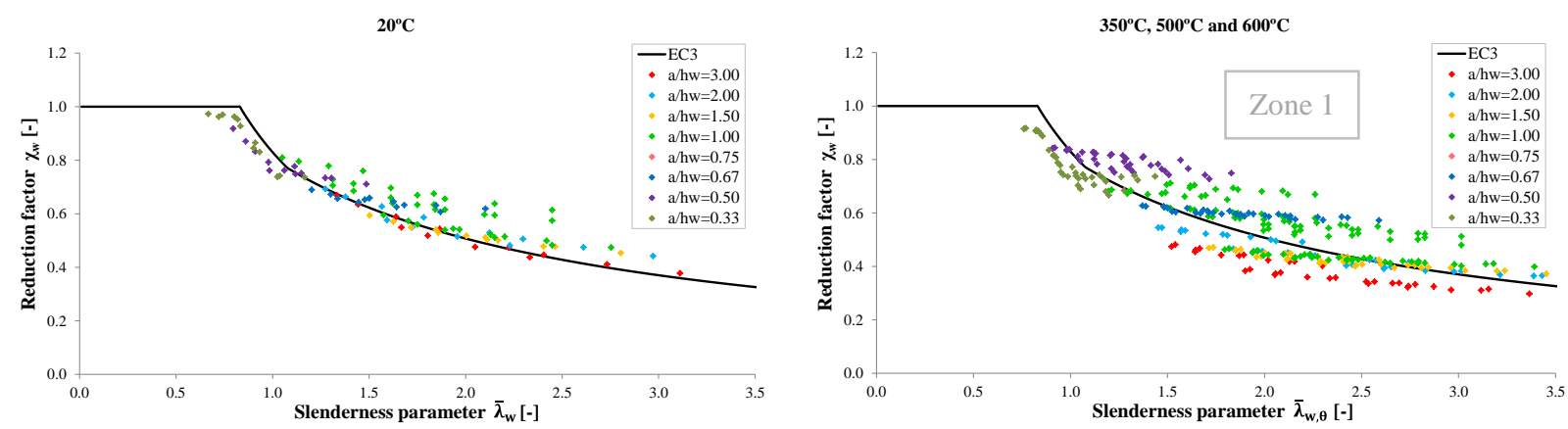

Fig. 4 Contribution from the web to shear buckling
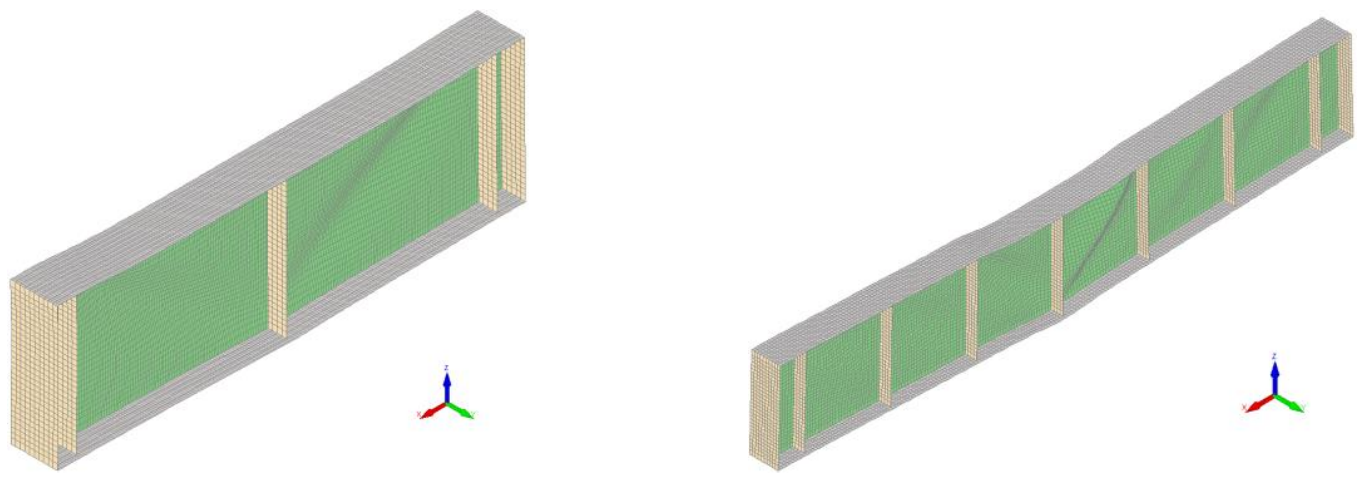

Fig. 5 Deformed shape at the failure moment of plate girders I-600x4.0+200x12.0_S355_500 ${ }^{\circ} \mathrm{C}$ and $\mathrm{I}-300 \times 2.5+100 \times 10.0 \_\mathrm{S} 3555500^{\circ} \mathrm{C}$

Fig. 3 shows that at normal temperature the design rules of Part 1-5 of EC3 are on the safe side for the most part of the results, with exception of the plate girders with a slenderness parameter lower than 1.0. However, it is possible to observe a substantial part of unsafe results at elevated temperatures. From the results of Fig. 4, it can be concluded that at $20^{\circ} \mathrm{C}$ the design curve of EC 3 is on the safety side for the most part of the analysed beams. At elevated temperatures, one can observe that, for a significant part of the analysed plate girders, the EC3 shear buckling curve overestimates the resistance from the web to shear buckling at elevated temperatures. Therefore, the application of the reduction factors for stress-strain relationship of steel at elevated temperatures is not enough and the analytical expressions to check the ultimate shear capacity of plate girders 
should be improved for a more accurate and safe evaluation in fire situation. Note that in the EC3 design curve for the web resistance to shear buckling it was used $\eta=1$ (factor depending on the steel grade which also corresponds to the plateau on the buckling curve) instead of the EC3 recommended value $\eta=1.2$. This was due to the fact that the applied material model does not take into account the increase of $20 \%$ of the shear yield strength due to strain hardening (Beg et al., 2010).

\section{CONCLUSIONS}

The ultimate shear strength of transversely stiffened plate girders with rigid end posts subjected to elevated temperatures has been studied. A parametric numerical study has been conducted and a comparison between the numerical results and the EC3design rules was made. As no explicit rules are given in Part 1-2 of EC3 for the shear safety verification in case of fire, a methodology based on the application of the design rules at normal temperatures adapted to fire situation using the reduction factors for the steel stress-strain relationship at elevated temperatures was used. At $20^{\circ} \mathrm{C}$, it was observed that the provisions from Part 1-5 of EC3 are adequate, with exception of plate girders with a slenderness parameter lower than 1. However, it was shown that at elevated temperature this methodology is not conservative and it should be improved to perform the safety evaluation of plated steel structures under fire. Additionally, it was observed that plate girders exhibiting a shear dominant failure at $20^{\circ} \mathrm{C}$ may exhibit a bending dominant failure or a failure caused by the interaction between shear and bending when subjected to elevated temperatures.

\section{ACKNOWLEDGMENTS}

This research work was funded by the Portuguese Government through the FCT (Foundation for Science and Technology) under the PhD grant SFRH/BD/85563/2012 (POPH/FSE funding) awarded to the first author.

\section{REFERENCES}

Beg D., Kuhlmann U., Davaine L., Braun B, 2010. Design of Plated Structures - Eurocode 3: Design of Steel Structures, Part 1-5: Design of Plated Structures", ECCS - Eurocode Design Manuals.

CAST3M, 2012. CAST3M is a research FEM environment; its development is sponsored by the French Atomic Energy Commission. <http://www-cast3m.cea.fr/>

CEN, 2005. EN 1993-1-2, Eurocode 3: Design of Steel Structures. Part 1-2: General rules - Structural fire design.

CEN, 2006. EN 1993-1-5, Eurocode 3: Design of Steel Structures. Part 1-5: Plated Structural Elements.

CEN, 2011. EN 1090-2:2008+A1, Execution of steel structures and aluminium structures - Part 2: Technical requirements for steel structures.

Couto C., Vila Real P., Lopes N., 2013. RUBY an interface software for running a buckling analysis of SAFIR models using CAST3M, University of Aveiro.

ECCS, 1984. Ultimate limit state calculation of sway frames with rigid joints, European Convention for Constructional Steelwork, Technical Committee 8 - Structural Stability, Publication no. 33.

Franssen J.M., 2005. SAFIR, a thermal/structural program modelling structures under fire, Engineering Journal, 42(3), p. 143-158.

Franssen J.M., Vila Real P., 2010. Fire Design of Steel Structures, ECCS Eurocode Design Manuals, Brussels: Ernt \& Sohn A Wiley Company, 1st Edition.

Höglund T., 1997. Shear buckling resistance of steel and aluminium plate girders, Thin-Walled Structures, 29(1-4), p. 13-30.

Reis A., Lopes N., Vila Real P., 2013. Numerical modelling of steel beams subjected to shear buckling at both normal and elevated temperature (in Portuguese), in IX Congresso de Construção Metálica e Mista, p. II-705-716.

Saliba N., Real E., Gardner, L., 2014. Shear design recommendations for stainless steel plate girders, Engineering Structures, 59, p. 220-228. 